\title{
Sobre respuestas e interpretaciones paradójicas
}

Las encuestas de opinión están llenas de respuestas y resultados paradójicos, al menos aparentemente. $\mathrm{Y}$ decimos aparentemente porque lo que es contradictorio, incoherente y hasta inverosímil para algunas personas, quienes pueden llegar a juzgar como sesgado un resultado; para otras, para quienes lo dicen de esa manera, no es más que la expresión más lógica de su forma de ver la realidad. Este comentario pretende dar respuesta a las preguntas formuladas por A. M. respecto a las encuestas de opinión y lo paradójico de algunas respuestas (ver $E C A, 1994,552$, pp. 1111-1113).

Comencemos recordando qué son las encuestas o sondeos de opinión pública. En general y de forma sencilla, se puede decir que los sondeos de opinión son un método de las ciencias sociales para recoger la opinión de una comunidad social, sea ésta un barrio, una asociación, una metrópolis o un país. Como cualquier método de investigación de ciencias sociales, en el fondo, las encuestas obtienen una imagen de la realidad social de un lugar y en una época determinados. Sin embargo, como tales, hay que recordar en principio que ningún método tiene la capacidad de recoger la realidad como un todo; en términos fenomenológicos podemos sólo obtener partes de la realidad y esas imágenes están estrechamente vinculadas con el espejo a través del cual se mira. En segundo lugar, y en esa misma línea, hay que recordar que si existe una realidad que los sondeos de opinión pública recogen, esa es la realidad social subjetiva, el mundo de las representaciones sociales y del pensamiento compartido. No podemos esperar que la forma en que las personas ven su mundo y se comportan hacia él constituya una copia fiel y adecuada de lo que conocemos como realidad objetiva. Por medio de las encuestas de opinión es posible identificar la forma en que los ciudadanos ven la realidad desde su propia perspectiva, a veces fragmentada, a veces compartida. Todo lo anterior es básico para entender las realidad de la cual nos hablan las encuestas. Hechas estas aclaraciones, ocupémonos de las observaciones puntuales de A. M.

La UCA viene preguntando a la población sobre el problema principal del país a partir de la fundación del IUDOP en 1986. Desde entonces ha habido una consulta constante para conocer el pulso de los problemas nacionales. Durante la década de los ochenta, los principales problemas nacionales estaban referidos a dos grandes cuestiones: la situación económica y la guerra. La preocupación por la economía se mostraba bajo distintos aspectos. Falta de trabajo, alto costo de la vida, pobreza o simplemente crisis económica eran las distintas caras de un mismo fenómeno y las distintas expresiones de una preocupación casi generalizada, sólo en ocasiones desplazada por la guerra. Cuando los salvadoreños no se estaban preocupando por la situación económica del país, lo hacían por la violencia generada por el conflicto armado y viceversa. Al finalizar la guerra, los salvadoreños dejaron de desvelarse por la violencia política fruto de la guerra, pero en su lugar comenzaron a preocuparse por la violencia común 
resultado de la ola delincuencial; en un primer momento durante la transición, el dilema por la situación económica no sufrió detrimento, es más, en ciertos momentos, tres de cada cuatro salvadoreños se preocupaban por el tema económico y sólo uno se preocupaba por la violencia delincuencial. Sin embargo, a medida que ha ido pasando el tiempo y con la falta de soluciones efectivas al problema de la criminalidad, la angustia de los salvadoreños por la delincuencia ha ido creciendo significativamente. Según las encuestas más recientes, los niveles de preocupación por la violencia delincuencial han superado por mucho margen el mayor nivel de preocupación expresado por la guerra en sus momentos más críticos.

Ahora bien, estos problemas tan reiteradamente manifestados y tan conocidos por los ciudadanos a través de los años tienen un doble carácter. A pesar de que las preguntas se refieren a los problemas nacionales, las respuestas más comunes tienen la característica de referirse tanto a la situación del país como a la situación individual del consultado. Cuando la persona responde que la delincuencia es la principal dificultad nacional no sólo toma en cuenta su lectura de la situación general - los medios hablan de delincuencia diariamente-; sino también, y a veces sobre todo, toma en consideración sus problemas particulares -el peligro de sufrir un atraco al regresar a su casa de noche. La historia de sondeos ha revelado que preguntar sobre el principal problema del país deja respuestas en las cuales tiene mucho que ver la propia experiencia y las condiciones inmediatas de vida.

¿Por qué los salvadoreños, en la actualidad, ubican a la delincuencia como el principal problema nacional en lugar de la pobreza? Desde una óptica estructural, ciertamente la pobreza constituye un problema anterior y mucho mayor que la delincuencia, es más, la delincuencia es producto de la miseria. Esta afirmación, sencilla y que parece ahora tan obvia, le ha costado a los economistas y a los sociólogos años de estudio y cientos de páginas de reflexión y debate. Sin embargo, desde la óptica del ciudadano común, en la que se pondera más lo que impone la cotidianeidad, es probable que sea más apremiante dedicarse a la cuestión de la delincuencia, la cual pone la propia vida en peligro, que dedicarse al problema de la pobreza con la cual se ha aprendido a vivir. Y es que las repetidas consultas de opinión pública suelen demostrar que la gente suele privilegiar lo coyuntural sobre lo estructural, en parte porque no disponen de la formación necesaria como para hacerlo, y en parte porque a veces lo coyuntural es tan agudo que no ocuparse de ello es lo más cercano a un estado de inconciencia suicida. Esto no quiere decir que los desposeídos no vean a la pobreza como un problema ni mucho menos que ignoren su calidad de pobres, simplemente quiere decir que están más preocupados por sobrevivir cada día, por terminar el día con sus pocos bienes o con vida que por la miseria con la cual viven desde que nacieron. Desde esta perspectiva no resulta contradictorio que sean las personas de los estratos ascendentes de la sociedad las que evalúen, aunque sea levemente, con mayor frecuencia la pobreza como problema nacional; su formación y sus condiciones de vida les da tiempo para ver el lado estructural de la situación y pasar por alto los aspectos formales. Por otro lado, ciertamente la delincuencia constituye la dificultad individual más citada por todos los sectores sociales salvadoreños, pero en términos globales lo que más sigue preocupando a los salvadoreños es la situación económica. Inflación, desempleo y pobreza son las distintas formas de caracterizar y de reconocer desde la propia perspectiva el problema de la economía salvadoreña.

En otro orden, A. M. encuentra paradójico también el hecho de que las personas que más señalan el problema de los servicios básicos son aquellas que ocupan el sector medio-alto y no los que sufren históricamente de tal carencia. Más aún, en agosto de 1993 el IUDOP realizó una encuesta sobre necesidades sociales, las respuestas resultaron muy sorprendentes y no menos contradictorias. Por ejemplo, el 55 por ciento de los salvadoreños se mostraron satisfechos con el servicio de agua que les proporciona ANDA, es más, el 77.8 por ciento de los habitantes de las zonas marginales y el 57.4 por ciento de los campesinos que son servidos por el sistema de ANDA mostraron agrado por el servicio. De igual 
forma, el 60 por ciento de los consultados estaban satisfechos de la atención en salud que brinda el gobierno (recuérdense el Hospital Rosales o el Hospital Psiquiátrico) y el 65.1 por ciento de las personas que habitan en zonas urbanas y que son atendidas por el tren de aseo estaba contento con el servicio de recolección de basura (93.9 por ciento entre los marginales). ¿No resulta esto aún más incongruente si lo comparamos con la realidad? ¿No es acaso obvio que el servicio de agua en la mayoría de poblaciones del país es extremadamente deficiente? ¿Por qué los más pobres se sienten satisfechos con un servicio malo? ¿Es posible que los marginales se sientan satisfechos por un "chorro" para toda la comunidad? ¿No están las ciudades llenas de promontorios de basura y de focos de insalubridad? ¿No es todo esto paradójico? A simple vista sí. Sin embargo, la explicación a esta aparente incongruencia tiene que ver con las realidades y expectativas de cada sector social. Lo que puede resultar malo o deficiente para un sector, es positivo y satisfactorio para otro. El marginal o el campesino pueden sentirse muy contentos de que cerca de su casa (a una cuadra, a una "media legua") exista un "choпro" de agua potable, aunque éste sólo funcione en la madrugada; en cambio, al habitante urbano de clase media le puede resultar muy irritante que deba levantarse temprano para poder realizar su aseo personal aunque sea en el baño particular de su habitación. El campesino puede sentirse muy satisfecho de que el gobierno haya decidido construir un puesto de salud en el caserío en el que vive, aunque el médico sólo llegue el martes y en los días restantes la atención esté a cargo de un bachiller en salud; en cambio, el residente de una colonia de clase media-alta se sentirá ofendido por la necesidad de esperar su turno en una fila para ser atendido en un hospital de la ciudad. En estas condiciones, no resulta paradójica la insatisfacción de los más prósperos. Los pobres, los desposeídos, los que han aprendido a vivir sin comodidades, reciben con beneplácito cualquier servicio, por deficiente que sea, que les ayude a sobrellevar sus precarias condiciones de existencia.

Lo anterior obviamente sùgiere prudencia hacia las encuestas. Si partimos de que cada sector

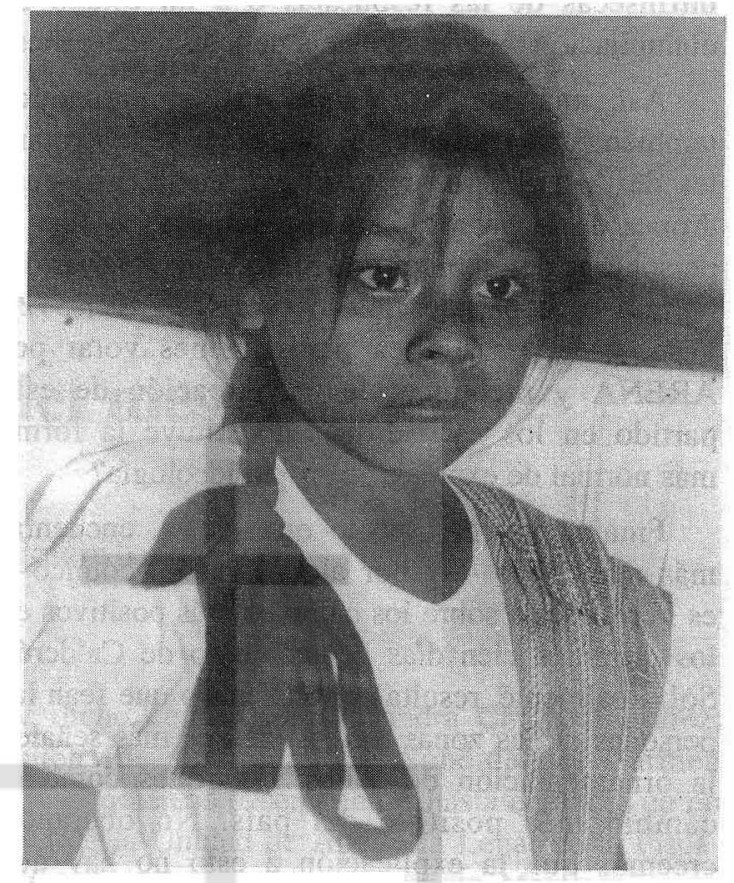

- grupo de personas ve las cosas de diferente manera, las respuestas, aunque iguales, no siempre pueden ser directamente comparables entre sí. De ahí que cualquier análisis serio que se haga sobre los sondeos de opinión pública no sólo debe presentar los resultados generales que aluden a la totalidad de la población, sino también debe mostrar las diferencias por sectores sociales. Al hacerlo de esa manera se tiene la precaución de no caer en generalizaciones que ciertamente pueden dar una idea sesgada del pensamiento social o de la opinión pública. Esto tiene también su relevancia para los que estudian los problemas económico-sociales del país y para los políticos. Debemos decir de nuevo que los resultados de las encuestas deben ser vistos, analizados e interpretados desde las perspectivas de los que las responden, no desde la perspectiva particular. Intentar analizar un discurso desde la lógica de otro crea incoherencias y confusión. Si con nuestros artículos e informes no hemos logrado que el lector entienda la perspectiva del salvadoreño común, ciertamente hemos fallado en ofrecer los elementos suficientes para ello, en la presentación de los resultados, pero difícilmente podemos pensar que se deba a incoherencias 
intrínsecas de las respuestas o a un estado de obnubilación de la conciencia de los salvadoreños.

Así, una encuesta puede resultar paradójica también cuando revela que una parte de los votantes de ARENA reconoce la existencia de escuadrones de la muerte e incluso implica en ellos a personeros del gobierno de turno, a personeros del partido o al partido mismo (ver ECA 541-542). Pero, ¿será paradójica para quienes votar por ARENA y reconocer la participación de este partido en los escuadrones constituye la forma más normal de expresar la propia ideología?

Finalmente, el aspecto que A. M. encuentra más paradójico -y por alguna razón, cómicoes la respuesta sobre los cambios más positivos en los primeros cien días del gobierno de Calderón Sol. Realmente, resulta contradictorio que sean las personas de las zonas rurales las que más señalen la ornamentación de calles y parques como el cambio más positivo del país. No obstante, creemos que la explicación a esto no hay que buscarla en la muestra o en las cuotas asignadas a cada sector social, el peso de éstas ha sido definido con fidelidad a los datos del censo que indican, por ejemplo, que la población rural que vive fuera de los municipios ronda el 35 por ciento. Más bien, la explicación tiene que ver con la tarea de codificación y agrupamiento de las respuestas abiertas. Bajo el enunciado de "arreglo y ornamentación de calles, parques y carreteras" se agrupó una serie de respuestas cuyo sentido era precisamente el mejoramiento de vías y lugares públicos y esto se hizo así porque la mayor parte de las respuestas tenía un sentido de estética metropolitana; la gente que afirmaba "han arreglado la calle" también fue incluida dentro de este ítem, pero ésta sólo representaba el 36 por ciento de las respuestas incluidas en esta categoría. Al ver los datos desde el rubro rural, el arreglo de calles y parques aparece como la respuesta más común, pero hay que decir que en conjunto esta respuesta se dio más en los sectores urbanos y el sentido más cercano de la misma se refiere al dado por los citadinos.

Con todo, estamos de acuerdo con A. M. de que las encuestas de opinión tienen limitaciones importantes, ignorarlas sería pecar de imprudente. Revisar y cuestionar los resultados es, por lo tanto, lo más sensato. Sin duda, las limitaciones más comunes que suelen tener las encuestas vienen de la forma en que se estructura el cuestionario, se distribuye la muestra y se seleccionan los sujetos; las observaciones hechas por A. M. a nuestro artículo tienen que ver más con la forma en que la gente articula su discurso en función de su realidad, que con aquellos errores metodológicos que pueden invalidar la investigación. Aunque ciertamente, hemos de aceptar la responsabilidad por no haber sabido presentar los resultados de una forma clara y comprensible para evitar las contradicciones.

IUDOP 